\title{
O TRABALHO DOS PROFESSORES EM QUESTÃO*
}

\author{
Maria Drosila Vasconcellos
}

$\mathcal{V}$ ma análise bibliográfica em educação, nos países industrializados, mostra a importância do trabalho dos professores, reconhecido como um dos principais fatores de sucesso escolar dos alunos. Apesar dessa importância e do grande número de professores, pois estes constituem uma das categorias profissionais mais numerosas em quase todos os países, o trabalho que eles realizam aparece ainda obscuro ou confuso. Há quatro séculos que a atividade escolar se desenvolveu nos países europeus e hoje, na maioria deles, os professores estão na primeira linha na perenização do sistema escolar. A idéia mesmo de desenvolver uma atividade especifica se integrou progressivamente na cultura moderna, com a finalidade de transmitir conhecimentos e valores próprios de cada sociedade, fazendo-se parte integrante de todas as sociedades organizadas. Os professores tiveram mesmo um papel importante na Alemanha prussiana ou na França, no fim do século XIX, ou no período de pós-guerra, e eram considerados como ponta de lança na modernização da sociedade pela transmissão de novas idéias ou ideais.

O impacto da educação tanto na economia como na constituição do espírito de cidadania na sociedade é atualmente incontestável. E, portanto, o trabalho exercido pelos professores é ainda considerado como fruto de capacidades pessoais, ligadas mais aos traços de personalidade ou da "motivação" que levam os indivíduos a abraçar essa carreira, sem reconhecer as competências que dispóem para

\footnotetext{
* Resenha do livro de Maurice Tardif \& Claude Lessard, Le travail enseignat au quotidien. Expérience, interactions humaines et dilemmes professionnels (Bruxelles: De Boeck Université, 1999. 575p.).

** Professora de Sociologia da Educação da Universidade Lille, França. E-mail: vasconcellos@wanadoo.fr
} 
exercer uma profissão como outra qualquer. Vários trabalhos de pesquisadores, tanto no Brasil como em países anglo-saxóes ou de origem francesa, se dedicaram à atividade pedagógica, principalmente na relação professor-aluno ou na forma triangular de relação: professorsaber-aluno. Porém, nota-se a ausência de um trabalho de análise da atividade do professorado no exercício cotidiano no ensino secundário. Sem duvida, o ato de "dar aulas" é fundamental, envolvendo o trabalho de preparação, de correções de provas e o empenho de formar atitudes dos alunos com relação aos estudos. O trabalho quotidiano dos professores, em cada colégio, envolve também as relações com os colegas, de forma organizada ou informal, com a administração, com os orientadores ou com os inspetores, correspondendo a uma carga horária pouco analisada.

Organizado por dois autores canadenses, Maurice Tardif e Claude Lessage, especialistas em educação, o livro vem preencher a ausência de pesquisa nessa área. Numa obra importante, seja pelo volume (575 páginas), seja pelo tipo de trabalho realizado, os autores estudaram a profissão de professor, baseando-se num tipo de demarcha própria à Sociologia do Trabalho, oferecendo assim uma análise objetiva das atividades exercidas por professores, como os sociólogos do trabalho tratam tantas outras profissões, principalmente quando baseadas na relação social a outrem. Um dos parâmetros da Sociologia do Trabalho é de tratar o exercício profissional concreto através da defasagem entre o trabalho prescrito e o trabalho efetivamente realizado. Assim, as condiçôes sociais desse exercício e a influência dos diversos atores aqui colaboram na realização do ato educativo.

Neste livro, o resultado é uma importante análise construída em torno de três partes: a organização do trabalho do professor, o processo do trabalho do professor e o ensino como trabalho coletivo. Eles estudam assim a estrutura do sistema escolar, as finalidades prescritas e o avesso dessas intenções pela dependência do ensino à "forma escolar": a organização do tempo, marcada pela divisão das disciplinas escolares, as práticas pedagógicas induzidas pela tradição da relação professoraluno, as avaliações ou notações e as decorrências dessas práticas na carreira escolar de cada aluno. Neste aspecto, os autores conseguiram, por meio de uma importante pesquisa realizada com professores de diversos tipos de colégio, descrições sobre a carga de trabalho que lhes é atribuída, do tempo de preparação das aulas, das tarefas exercidas dentro dos colégios, ligadas à organização social escolar, além da fastidiosa correção de provas ou de exercícios cotidianos dos alunos. A 
organização social de cada colégio, dispondo de uma fraca formalização, exige, na realidade, um empenho maior dos professores para que este espaço funcione dentro de uma certa “ordem escolar". Baseada em princípios implícitos e nas normas ou regras dos regulamentos internos, ou nas diretivas ministeriais que oferecem um quadro geral, os professores se empenham, a partir deste quadro, a construir cotidianamente a "ordem escolar", a fim de assegurar o bom funcionamento do colégio. Essa construção apóia-se principalmente nas relações entre colegas, baseadas numa "afinidade" de idéias, visando fazer com que o estabelecimento escolar torne-se uma "boa escola", condição de realização e de sucesso profissional desse grupo social.

Os autores desfazem assim a ilusão do trabalho autônomo do professor realizado na sala de aula: longe das idéias românticas de uma profissão em que a autonomia professoral marcou várias gerações, explicando o sentimento de "vocação" para essa atividade, o trabalho dos professores é cada vez mais codificado, racionalizado pelas diretivas ministeriais, prescrevendo em detalhe o programa a ser desenvolvido e a progressão a ser levada em conta. E, sem dúvida, o papel importante do material pedagógico induz certas práticas, nem sempre aceitas pelos professores, mas pelas quais se sentem "prisioneiros" por conta da imposição da mídia e das famílias.

A importância da hierarquia das disciplinas nos programas, quase sempre negligenciada nas pesquisas desse gênero, implica exigências diversas no desempenho dessa profissão: o professor que é responsável pelas matérias consideradas "nobres" no programa escolar (matemática, por exemplo) é diversamente avaliado pela administração escolar, pelos alunos e pelas famílias. Entretanto, os que são responsáveis por matérias pouco valorizadas no cômputo geral devem fazer prova de maestria para "prender" a atenção dos alunos e estimular seu empenho nos saberes transmitidos.

Por meio da análise da evolução do sistema escolar, pela relativa democratização do público do secundário e pela complexificação dos objetivos do ensino, o professor é colocado diante de uma atividade em completa mutação. O aumento de tarefas, os novos tipos de comportamentos juvenis, seja com relação à autoridade professoral, seja com o significado do ato de aprender, levam os professores a construir regularmente a "ordem escolar".

A relação com os pais de alunos se modifica: o comportamento de "consumidor" se estendeu na medida em que as incertezas do 
futuro profissional ou social das camadas médias e altas da sociedade se tornaram realidade. Os autores se referem, nesses casos, à pesquisa de campo realizada: incompreensōes e tensōes aparecem entre professores e familiares dos alunos, para os quais a idéia da "eficiência" dos saberes transmitidos ganha uma significação diferente para cada um.

Os autores chamam a atenção para o papel dos sindicatos mesmo se eles perderam a influência dos áureos tempos quando desfrutavam de um peso junto às instâncias ministeriais, podendo impor ou arbitrar as orientaçoes de políticas de ensino ou de desenvolvimento de carreiras dos professores. Entretanto, apesar do enfraquecimento, os sindicatos preservam o papel importante na gestão dessas carreiras e nas orientações consideradas contrárias aos objetivos que defendem (forma de seleção dos alunos, conteúdos dos programas, política de profissionalização do ensino secundário etc.) Aqui, o encontro de interesses entre professores e pais de alunos, ambos de mesma origem social (classes médias ou superiores intelectualizadas), permite o sucesso desse tipo de ação sindical. Por meio dessa ação, o trabalho coletivo dos professores aparece reforçado, favorecendo o sentimento de coesão do grupo profissional.

De uma maneira geral, os autores mostram que a atividade dos professores é um exercício profissional complexo, composto, na realidade, de várias atividades pouco visíveis socialmente. A experiência constitui a expressão de aprendizagem profissional e, pelo contato diário com os alunos e os colegas, torna-se o modo de adquirir competências profissionais que se traduzem no perfil do "bom professor".

Outro fator importante é apontado pelos autores na construção dessa profissão: as condições sociais de cada estabelecimento escolar, fruto da situação local em que o colégio está inserido, correspondendo ao tipo de público escolar junto aos quais eles exercem o ensino. O sentimento de satisfação ou de esgotamento moral com relação à profissão é fortemente ligado a essas condiçôes sociais. A Sociologia do Trabalho já havia demonstrado, com riqueza de detalhes, em outros campos profissionais (campesinato, operários, executivos ou mesmo altos funcionários) a importância dessas condições sociais no desempenho das atividades profissionais. Aqui, o interesse é a demonstração de que as dificuldades observadas estão presentes em vários países, dispondo de condiçôes sociais, políticas ou econômicas bem diferentes entre si, exprimindo um problema mais profundo que seriam a crise da educação e as implicações desta crise no trabalho dos professores e no trabalho educativo em geral. As transformaçōes nas políticas educativas na maioria dos países, caracterizadas pela extensão da escolaridade secundária, 
criaram novas tensões devido principalmente ao aprofundamento das desigualdades entre as "boas escolas" e as outras. Mesmo num país onde o ensino é obrigatório e gratuito, distribuído igualmente a todo território nacional, não se impediu que os contrastes sociais se instalassem entre o "centro" e a "periferia". A tendência a aprofundar as diferenças sociais conduz, de um lado, à competição entre as "boas escolas" e, de outro, a deixar aos professores a dura tarefa de lidar com o público desfavorecido das escolas da periferia. Cabe a eles encontrar os meios de exercer a profissão e obter resultados de performance avaliados por critérios nacionais generalizados.

Este rico trabalho desenvolvido por Tardif \& Lessage, dedicado aos professores, pode se tornar exemplar para outras profissōes, baseadas nas relaçōes sociais e submetidas às mesmas condiçōes de tensōes ou de contradiçôes, engendradas pelas atuais políticas sociais, nas quais a lógica mercantil ganha espaço contra a lógica elaborada com base em princípios que favorecem as igualdades sociais. 